adults: I - chronic persistent asthma. BMJ 1990; 301: 651-3.

31. McCarthy T P. Use of 'Nebuhaler' and face-mask in young asthmatic children. Lancet 1990; 335: 983-4.

32. Neville R G, Clark R C, Hoskins G et al. National asthma attack audit 1991-2. BMJ 1993; 306: 559-62.

33. The North of England evidence based guidelines development project. BMJ 1996; 312: 762-6.

34. Livingstone A E. Do people living near inner city main roads have more asthma needing treatment? Case control study. BMJ 1996; 312 : 676-7.

35. Jackson C, Lipworth B. Optimizing inhaled drug delivery in patients with asthma Br J Gen Pract 1995; 45: 683-7.

36. Jones A, Bowen M. Screening for childhood asthma using an exercise test. Br J Gen Pract 1994; 44: 127-31.

37. Jones A. Screening for asthma in children. Br J Gen Pract 1994; 44: $179-83$

38. Levy M L, Stephenson C, Maslen T. Comparison of short courses of oral prednisolone and fluticasone propionate in the treatment of adults with acute exacerbations of asthma in primary care. Thorax 1996; 51: 1087-92.

39. Bryce F P, Neville R G, Crombie I K et al. Controlled trial of an audit facilitator in diagnosis and treatment of childhood asthma in general practice. $B M J 1995,310: 838-42$.

40. McCowan C, Neville R G, Crombie I K et al. The results from a four year study. Br J Gen Pract 1997; 47: 156-60.

41. White $\mathrm{P}$, Atherton A, Hewett G et al. Using information from asthma patients: a trial of information feedback in primary care. BMJ 1995; 311: 1065-9.

42. Price D B. Inhaled steroid prescribing over seven years in a general practice and its implications. Eur Resp J 1995; 19: 463s. 43. Feder G, Griffiths C, Highton C et al. Do clinical guidelines introduced with practice based education improve care of asthmatic and diabetic patients? A randomised controlled trial in general practices in east London. BMJ 1995; 311: 1473-8. 44. Naish J, Sturdy P, Toon P. Appropriate prescribing in asthma and its related cost in east London. BMJ 1995; 310: 97-100. 45. Griffiths C, Sturdy P, Naish J et al. Hospital admissions for asthma in east London: associations with characteristics of local general practices, prescribing, and population. BMJ 1997; 314: 482-6. 46. Grampian Asthma Study of Integrated Care (GRASSIC). Integrated Care for asthma: a clinical, social and economic evaluation. $B M J$ 1994; 308: 559-64.

47. Grampian Asthma Study of Integrated Care (GRASSIC) Effectiveness of routine self-monitoring of peak flow in patients with asthma. BMJ 1994; 308: 564-8.

48. Grampian Asthma Study of Integrated Care (GRASSIC)

Reducing hospital admission through computer supported

education for asthma patients. BMJ 1994; 308: 568-72.

\title{
The differential diagnosis of COPD and asthma
}

\author{
P Buttery and T Higenbottam
}

\begin{abstract}
$\mathrm{C}$ hronic obstructive pulmonary disease (COPD) is a disorder characterised by irreversible airflow obstruction, whereas in asthma the airway obstruction is reversible, either spontaneously or with treatment. ${ }^{1}$ COPD patients have reduced maximum expiratory flow and slow forced emptying of the lungs; features which do not change markedly over several months. In most patients the airflow limitation is slowly progressive and irreversible. ${ }^{2}$
\end{abstract}

From the clinician's point of view, perhaps the biggest problem with these two respiratory disorders is that the clinical findings often overlap and making diagnosis difficult.

\section{DIFFERENTIAL DIAGNOSIS}

It is important to realise that COPD embraces a variety of clinical pictures which range from non-smokers with severe steroid-dependant asthma to heavy smokers with bronchitis and advanced emphysema. Whilst there is an overlap between asthma and COPD related to smoking, they are different diseases with different aetiologies, pathologies, natural histories, and responses to treatment. ${ }^{3}$

Diagnostic confusion or failure to respond to treatment are indications for referral to a specialist. In all patients presenting with wheezing, breathlessness, or airway obstruction, the health professional should consider:

1. Whether the airways obstruction is localised (e.g. due to cancer, a foreign body, post-tracheostomy stenosis, vocal chord dysfunction with wheeze), or generalised.

2. If the airways obstruction is generalised, whether it could be due to asthma (in which case it is predominantly reversible) or to COPD (when the obstruction is largely irreversible), or to a combination of the two. Alternatively, one of the more unusual causes such as bronchiectasis,

\section{Table 1: Clinical features distinguishing COPD and asthma}

\begin{tabular}{ll}
\hline COPD & Asthma \\
\hline Little variation in PEF & PEF variability \\
Poor/no reversibility to oral steroids & Good reversibility to oral steroids \\
Poor/no reversibility to inhaled steroids & Good reversibility to inhaled steroids \\
Poor/no reversibility with bronchodilators & $\begin{array}{l}\text { Reversibility with bronchodilators } \\
\text { Chronic hypoxaemia }\end{array}$ \\
Aecreased diffusing capacity & \\
Emphysema on x-ray & \\
History of smoking &
\end{tabular}

obliterative bronchiolitis, or cystic fibrosis should be considered. ${ }^{3}$ The presence of bronchiectasis can be detected by high-resolution computed tomography (HRCT).

The most common distinguishing features of COPD are the chronicity of the condition and the limited response to conventional asthma treatment. However, there may be some clinical features which suggest one disorder rather than the other (Table 1).

\section{The use of spirometry in differential diagnosis} Spirometry is useful to assess the severity of COPD, to predict the prognosis and to assess the response to therapy. The presence of airflow limitation in COPD is recognised by a reduction in the ratio of the forced expiratory volume in one second $\left(\mathrm{FEV}_{1}\right)$ to the vital capacity (VC). ${ }^{2}$ Most modern spirometers are capable of producing an expiratory flow volume curve or loop. The flow volume curve is another way of showing forced ventilatory action and is obtained by plotting inspiratory and expiratory flow rates against lung volume.

The expiratory flow loop shows the peak expiratory flow (PEF) rate as expiration begins, with the flow rate gradually decreasing as the lungs empty, reaching zero
Patricia Buttery Clinical Nurse Specialist in Asthma

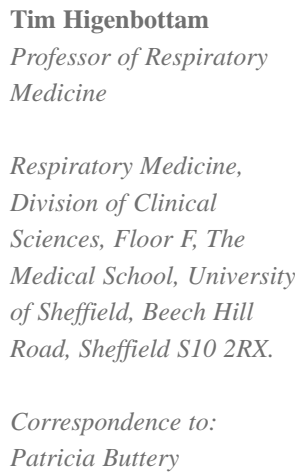

Asthma in Gen Pract 1997; 5(2): 20-2. 
Flow-volume curve examples, including pressure- and volume-dependent collapse

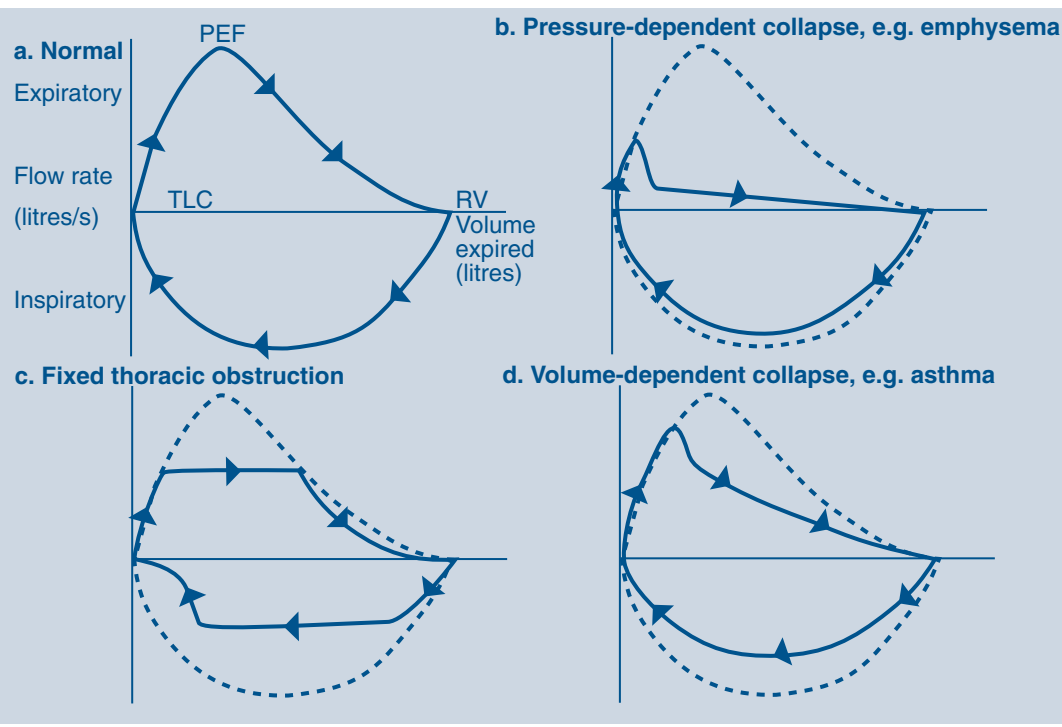

when the residual volume $(\mathrm{RV})$ is reached. The normal inspiratory flow loop is a semi-circular shape and shows the volume increasing from the RV through to total lung capacity (TLC).

\section{Deviations from normal flow volume curve}

Changes in the shape of these are seen in several clinical situations. In emphysema and severe airways obstruction the PEF is greatly reduced and a much smaller loop is seen.

\section{Static lung volumes}

Total lung capacity (TLC), residual volume (RV) and functional residual capacity (FRC) are all increased in COPD and are related to the degree of hyperinflation of the lungs. These findings can be helpful in distinguishing COPD from asthma.

\section{Gas transfer}

Carbon monoxide gas transfer capacity and co-efficient are both reduced in patients with symptomatic COPD, particularly those with emphysema.

\section{PEF measurement}

This provides a way of demonstrating that there is no spontaneous variation in the airflow obstruction in COPD. In these patients, in contrast to the situation in asthma, there is no diurnal variation. However, although measurement of PEF with a peak flow meter is simple and convenient, it gives less information on the severity of airflow obstruction than spirometry. This is particularly the case in advanced COPD where the PEF may be

Table 2: Risk factors for developing COPD

$\begin{array}{lll}\text { Degree of certainty } & \text { Environmental factors } & \text { Host factors } \\ \text { Established } & \begin{array}{l}\text { Cigarette smoking } \\ \text { Some occupational exposure }\end{array} & \alpha_{1} \text {-antitrypsin deficiency } \\ \text { Good evidence } & \begin{array}{l}\text { Air pollution } \\ \text { Poverty, low socio-economic status } \\ \text { Alcohol } \\ \text { Exposure to smoking in childhood }\end{array} & \begin{array}{l}\text { Low birth weight } \\ \text { Childhood respiratory infection } \\ \text { Atopy (high Ige) } \\ \text { Bronchial hyper-responsiveness } \\ \text { Family history }\end{array} \\ & \begin{array}{l}\text { Infection } \\ \text { Dietary deficiency of vitamin C }\end{array} & \begin{array}{l}\text { Genetic predisposition } \\ \text { Blood group A } \\ \text { Iga non-secretor }\end{array} \\ & & \end{array}$

reduced to a lesser extent than the $\mathrm{FEV}_{1}$. Also, as the PEF is effort dependent and in advanced disease affected by collapse of the airways, a peak flow meter should not be used without reference to spirometry.

Finally, measurement of the $\mathrm{FEV}_{1}$ with a spirometer enables a prediction to be made of the risk of the development of respiratory failure. An FEV less than $35 \%$ of the predicted value (often $<1.01$ ) denotes a high risk of respiratory failure and a poor chance of survival over three years.

\section{RISK FACTORS FOR DEVELOPING COPD}

A number of risk factors for the development of COPD have been identified (Table 2), with smoking being the most important. ${ }^{2,4}$

\section{Smoking}

There is little doubt now that cigarette smoking is the most important risk factor in the development of COPD. ${ }^{5}$ Cigarette smoking results in inflammatory cells being attracted into the lungs and stimulates the release of elastase, an enzyme which breaks down connective tissue in the lungs. The activity of elastase and other proteases is normally inhibited by $\alpha_{1-\text { anti- }}$ trypsin. However smoking inactivates $\alpha_{1}$-antitrypsin and alters the balance between enzyme and inhibitor leading to greater activity of elastase and more destruction of lung tissue. ${ }^{6}$

\section{Genetic factors}

In a small proportion of COPD patients the condition is associated with an inherited deficiency of $\alpha_{1}$-antitrypsin.

\section{Air pollution and occupational exposure}

The evidence that air pollution contributes to COPD is still unclear, but there is no doubt that some people are more susceptible than others. Occupational exposure to dust or fumes increases the risk of developing COPD. Those at risk include construction workers, grain handlers, cotton and paper mill workers and miners.

\section{Maternal and passive smoking}

It is very difficult to judge the extent to which passive smoking affects the lungs, but there is evidence to suggest that respiratory infections are more common in children whose parents smoke.

\section{Infections}

Pneumonia, whooping cough and bronchitis in the first two years of life are risk factors for the development of COPD in adults.

\section{Social class}

COPD is more common in families living in poor socio-economic circumstances. Poor housing, damp conditions and poor nutrition all add to the risk; the prevalence of smoking and occupational risk factors are also greater in poor social circumstances.

\section{Nutrition}

There is some evidence to link vitamin $\mathrm{C}$ deficiency with the development of COPD. The reason for this is unclear, but it is thought that vitamin $\mathrm{C}$ may help to protect against the destructive effects of smoking. ${ }^{8}$ It has also been suggested that a high fish intake may protect smokers from loss of lung function. 


\section{References}

1. British Thoracic Society, British Paediatric Association, Research Unit of the Royal College of Physicians of London et al. Guidelines on the management of asthma. Thorax 1993; 48: S1-24. 2. Siafakas N M, Vermeire P, Pride N B et al. Optimal assessment and management of chronic obstructive pulmonary disease (COPD). Euro Resp J 1995; 8: 1398-440.

3. British Thoracic Society, National Asthma Campaign, Roya College of Physicians et al. The British Guidelines on Asthma Management. Thorax 1997; 51: S1-21.

4. Silverman E K, Speizer F E. Risk factors for the development of chronic obstructive pulmonary disease. Med Clin North Am
1996; 80: 501-22.

5. Mak V. Chronic obstructive pulmonary disease (COPD). The UK perspective. Version 1.2. Chest Medicine On-Line 1996; http://www.priory.com/chest.htm.

6. Ogushi F, Hubbard R C, Vogelmeier C et al. Risk factors for emphysema. Cigarette smoking is associated with a reduction in the association rate constant of lung $\alpha_{1}$-antitrypsin for neutrophil elastase. J Clin Invest 1991; 87: 1060-5.

7. Whitehead M. Inequalities in health. In: Townsend P, Davidsen N, eds. The Black Report. London, Penguin 1988.

8. National Asthma and Respiratory Training Centre. Training manual for COPD, 1997.

\title{
Inhalation devices used in the treatment of asthma
}

\author{
E N Evans and P Ebden
}

$\mathrm{B}$ ritish Thoracic Society guidelines on asthma management ${ }^{1}$ encourage inhaled drug delivery. This review summarises the different delivery systems, including their equivalence in terms of drug delivery and bio-availability.

\section{AEROSOl INHALERS \\ Pressurised metered-dose inhalers (pMDIs)}

These are the most widely used inhalational devices. The canister is sealed with a metering valve, delivering respirable ( $<5 \mu \mathrm{m}$ in diameter) and larger particles. The drug is suspended in a propellant, which until recently consisted only of chlorofluorocarbons (CFCs), with added lubricants and surfactants. The dose of the inhaled drug delivered depends upon shaking the device to mix the contents. Various devices deliver up to four hundred doses, the canister's lifetime depends on the volume of drug delivered per actuation.

Advantages of pMDIs include resistance to moisture and low cost. One disadvantage is the difficulty in coordinating the actuation of the device with inhalation. Lung deposition from a pMDI, or modified pressurised aerosol (see below) is affected by the position of the inhaler in relation to the lips, lung volume at inhalation, inhaled flow rate (enhanced with rates of $30 \mathrm{l} / \mathrm{min}$ ) and breath-holding after inhalation for $10 \mathrm{sec}^{2}$ Other problems include the lack of a dose counter and the 'cold Freon' effect, with the patient stopping inhalation as the aerosol reaches the throat. Despite these problems, many patients can still use pMDIs satisfactorily.

Generic formulations of salbutamol and beclomethasone dipropionate (BDP) are available for use with pMDIs, but evidence regarding bioequivalence is limited. Although some studies of salbutamol pMDIs have shown significant differences in total delivered dose ${ }^{3}$ and significant differences in broncho-dilation; ${ }^{4}$ they have not been supported by other comparisons of salbutamol delivered by pMDIs. ${ }^{5}$ In these studies the statistical power is small and the methodology not stand-ardised. Three generic BDP preparations were reported to have different aerodynamic particle size distributions ${ }^{6}$ and hence the clinical effects may be different.
Breath-actuated metered-dose inhalers (BA MDIs)

These use pressurised canisters and therefore have many characteristics of pMDIs, including CFC propellants, no dose counter and the 'cold Freon' effect. The devices use springs for activation, which require priming and are triggered by the patient inhaling at flow rates of $30 \mathrm{l} / \mathrm{min}$ or more. BA MDIs eliminate the co-ordination necessary with pMDIs, but some patients are startled by the release of the spring causing glottic closure. This can be overcome by using a quieter mechanism, such as with Easi-Breathe $^{\circledast}$. The clinical efficacy of the BDP Autohaler ${ }^{\circledast}$ has been shown to be equivalent to a correctly used pMDI in asthmatics.?

\section{Chlorofluorocarbon-free metered-dose inhalers}

Chlorofluorocarbons (CFCs) cause destruction of the ozone layer. Although the Montreal Protocol ${ }^{8}$ demands the phasing out of CFC use, time has been allowed to develop alternative propellants for pharmaceuticals. Interest lies with two hydrofluoroalkanes, HFA 134a and HFA 227 which have different properties from CFCs. Each combination of drug and propellant needs to be assessed and developed for clinical safety, reliability and efficacy.

The first CFC-free pMDI is Airomir ${ }^{\circledR}$; a suspension of salbutamol sulphate in HFA 134a. Trials show this combination to be safe and effective with no dosage adjustment required compared with existing CFC inhalers, ${ }^{9}$ which are also suspension products. This may not apply to other CFC-free propellants with drugs reformulated in solution. Solution aerosols result in smaller droplets $(<2$ $\mu \mathrm{m})$ for some drugs (including corticosteroids), increasing lung deposition, which may require dose reduction..$^{10}$ The smaller particles cause less oropharyngeal deposition, making spacer use less important. Change in taste of the new propellant is expected, with a possible reduction in the 'cold Freon' effect. Airomir ${ }^{\circledast}$ does not contain a dose counter; the dose of salbutamol remains constant until the last two to three actuations, ${ }^{11}$ an advantage when determining if a device is empty. The development of patented CFC-free propellants has obvious financial implications for generic substitutions in pMDIs.

\section{Spacer devices}

Plastic spacers (holding chambers) were introduced for

\author{
Emrys Evans \\ Registrar in Medicine \\ 31 The Paddocks, Tonna \\ Neath, West Glamorgan, \\ SA11 3FD. \\ Philip Ebden \\ Consultant Physician and \\ Senior Lecturer in \\ Respiratory Medicine \\ Llanelli/Dinefwr NHS \\ Trust, Prince Philip \\ Hospital, Bryngwynmawr \\ Dafen, Llanelli, Carms \\ SA14 8QF. \\ Correspondence to: \\ Dr Evans
}

